\title{
Issues on the Translation of Certain English Collocations into Arabic: from Collocations to Free Constructions in the Target Language
}

\author{
Rafat Y. Alwazna ${ }^{1}$ \\ ${ }^{1}$ Department of European Languages and Literature, Faculty of Arts and Humanities, King Abdulaziz University, \\ Jeddah, Kingdom of Saudi Arabia \\ Correspondence: Rafat Y. Alwazna, Department of European Languages and Literature, Faculty of Arts and \\ Humanities, King Abdulaziz University, Jeddah, Kingdom of Saudi Arabia, P. O. Box: 14354, Jeddah 21424
}

Received: September 18, 2018

Accepted: September 27, 2018

Online Published: September 28, 2018

doi:10.5430/elr.v7n3p51

URL: http://dx.doi.org/10.5430/elr.v7n3p51

\begin{abstract}
The translation of collocations between different languages is not always an easy task, but can at times be a problematic and a challenging practice amongst linguists and translators/interpreters. The present paper argues that the translation of English collocations into Arabic can be a flexible practice if Arabic possesses the equivalent collocation while the literal meaning of the whole English collocation is intended. The translator can still find an appropriate equivalent collocation in Arabic, even if the literal meaning of the first word in the English collocation is not intended. This, however, requires the translator to find a word in Arabic that conveys the intended meaning of the word in English and collocates with the other Arabic word simultaneously. The paper also claims that the translator may resort to make use of a free construction in Arabic to stand for the English collocation concerned. This often takes place if Arabic does not possess an equivalent collocation to the English collocation as the literal meaning of the latter is not the intended meaning, the verbs in the former and the latter differ in terms of type and function and/or the verb in the former can convey the intended meaning of the whole English collocation.
\end{abstract}

Keywords: verb plus object collocation, adjective plus noun collocation, equivalent collocation, fixed expressions, free construction

\section{Introduction}

The mastery of collocation is deemed an important part in foreign/second language learning as well as in translation/interpreting. Translators/interpreters in particular and foreign/second language learners in general should pay careful attention to foreign/second language collocations. This is owing to the fact that L1 has significant bearing on the L2 production, including collocations, as investigated and confirmed by some scholars, such as Bahns \& Eldaw (1993) and Hussein (1990). Such scholars have found that L2 learners commit multiple mistakes when making up 12 collocations. The same notion may apply to novice translators/interpreters, particularly when rendering texts from their mother tongue into a foreign language.

Indeed, combining textual elements that do not collocate in a particular language may make the text look alien, foreign and exotic to the target reader, which may negatively affect its comprehensibility. This may also have a negative impact on the thematic structure of the text alongside the level of coherence and cohesion of the whole text. This is advocated by Hatim \& Mason (1997), who contend that collocation plays a significant role in the cohesion and coherence of texts.

The present paper addresses the concept of collocation, discussing and analysing the translation of certain English collocations into Arabic. It at the outset offers certain definitions of the concept of collocation, drawing a clear line between collocations and other idiomatic expressions. A relatively succinct theoretical account of collocation will next be provided, showing how collocation was first introduced by Palmer (1938), how it was then developed as a technical term by Firth (1957) and how different linguists later proposed different theories to deal with the concept of collocation. The paper then presents two different classifications of collocation made by different linguists. The first is suggested by Benson et al (1986) who divide collocations into lexical and grammatical collocations. The second classification is proposed by Newmark (1988) who asserts that collocation falls into three categories: verb plus object collocation, adjective plus noun collocation and noun plus noun collocation. 
A large section is next devoted to tackle the issues and problems in the translation of certain English collocations into Arabic. This section confirms that the problem in the translation of English collocations into Arabic arises when the receptor language does not possess an equivalent collocation to that of the source language. Two different English collocations have been meticulously examined and thoroughly studied when rendered into Arabic: these are verb plus object collocation and adjective plus noun collocation. The paper has profoundly discussed diverse cases of the aforementioned English collocations and how they can acceptably be translated into Arabic in all cases.

Finally, the present paper argues that the translation of English collocations into Arabic can be a flexible practice if Arabic possesses the equivalent collocation while the literal meaning of the whole English collocation is intended. The translator can still find an appropriate equivalent collocation in Arabic, even if the literal meaning of the first word in the English collocation is not intended. This, however, requires the translator to find a word in Arabic that conveys the intended meaning of the word in English and collocates with the other Arabic word simultaneously. The paper also claims that the translator may resort to make use of a free construction in Arabic to stand for the English collocation concerned. This often takes place if Arabic does not possess an equivalent collocation to the English collocation as the literal meaning of the latter is not the intended meaning, the verbs in the former and the latter differ in terms of type and function and/or the verb in the former can convey the intended meaning of the whole English collocation.

\section{Definition and Concept}

Collocation forms an important part of any language. It refers to the patterns of lexical items that co-occur (Mahadi, Vaezian \& Akbari, 2010, p. 25). Indeed, collocations are said to be words which come in sequence 'with a greater than random probability' (Bowker, 2002, p. 64). Collocation is a mixture of two or more words that appear together regularly in different contexts of languages. This runs in line with Robins (1967), who asserts that collocation is a regular association of lexical items in a particular language (p. 63). This is seconded by Hoogland (1993), who points out that collocation is deemed a lexical relationship that involves two or more lexical items following each other in a sequence as the use of a specific word, e.g. a noun, limits the choice of other words that can follow it, e.g. adjectives (p. 75).

Brashi (2009) claims that collocation points to the tendency of specific words that come together in a particular language, as opposed to other words in the same language which do not tend to come in sequence (p. 21). He goes on to confirm that the meaning of any particular collocation can generally be derived from at least one of its constituents (p. 21). Such crucial aspect of collocation is what draws a clear line between it and idioms whose meanings are nod deduced from the meanings of their constituents (Cruse, 1986, p. 37). For instance, the intended meaning of the idiomatic expression: 'football is not my cup of tea' resides in the fact that 'I do not enjoy playing football'. Needless to say, the literal meanings of the constituents of the above idiom are not intended and will never lead to the appropriate intended meaning of the idiom. However, the idiomatic meaning of the idiom, which has nothing to do with the literal meanings of its constituents, is the appropriate intended meaning. Conversely, the intended meaning of the collocation: 'to perform a task' is 'to do a job' or the like. Evidently, the literal meanings of the constituents of the above collocation, which may read as 'do/make/carry out/etc' and 'job/work/etc', do unquestionably lead to the appropriate intended meaning of the collocation.

\section{Brief Theoretical Account of Collocation}

The importance of the concept of collocation springs chiefly from the claim made by a number of linguists that all languages possess fixed forms and known expressions that are familiar to native speakers and are viewed by them as chunks of lexical items rather than individual words. Such expressions are used in written as well as in spoken language without change. One pivotal subarea of these expressions is known as collocation (Brashi, 2009, p. 22-23). A collocation is considered to be a link between lexical items. Such relation is deemed arbitrary as it is not based on rules, rather it is primarily grounded on common usage (Benson et al, 1986). The term 'collocation' was first introduced by Palmer (1938) in his well-known dictionary: 'A Grammar of English Words'. It then became a technical term, i.e. entered the linguistics terminology after the work of Firth (1957) who propounded the theory of 'meaning by collocation' (p. 194). He proposed in his theory that 'collocation' has a lexical meaning "at the syntagmatic level not at the paradigmatic level” (Firth, 1957, p. 196; Brashi, 2009, p. 23).

The difference between the syntagmatic relationship of lexis and the paradigmatic relationship resides chiefly in the notion that the former is concerned with the ability of a particular word to combine with a group of other lexical items, whilst the latter is composed of a set of lexical elements relating to the same word class and can be at the same time replaced by one another in a particular lexical and grammatical context (Brashi, 2009, p. 23). Hence, Firth's (1957) study of collocation focused primarily on the syntagmatic relationship, i.e. the meaning relationships between 
words, and not on the meaning of individual words, the main concern of the paradigmatic relationship. An example of the paradigmatic relationship according to the explanation given by Firth (1957) may lie in the relationship between the following two words: 'achieve' and 'accomplish', which generally mean 'yuhaqqiqu' in Arabic. It is noteworthy that both words belong to the same word class 'verb' and can replace one another in certain linguistic contexts as they are deemed synonymous. However, this paradigmatic relationship does not at all address the ability of one of these words to combine with the other word, the main focus of the concept of collocation. A good example of the syntagmatic relationships between lexical items was provided by Firth (1968) as an adjective-noun collocation: 'dark night'. He points out that one of the meaning of 'dark' is its collocation with 'night' and one of the meaning of 'night' is its collocation with 'dark' (Firth, 1968, p. 182; Brashi, 2009, p. 23). Based on the foregoing, Firth (1968) confirms the importance of recognizing the set of words that accompany a particular word if its meaning is to be completely studied.

Lyons (1966) rejected at the outset Firth's theory of 'meaning by collocation', arguing that a particular collocation cannot be comprehended from all the constituent parts that make up the expression in which the collocation is stated. He goes on to claim that part of the meaning of a single lexical item in the collocation may not hinge upon its association with other lexical item(s) in the same collocation. Indeed, Lyons's (1966) view of collocation is chiefly founded on a distributional theory, which is repugnant to Firth's (1957) theory of 'meaning by collocation'. On the contrary, Lyons (1977) seems to have changed his views as he asserts that there exists a high degree of interdependence between lexical items in the sense that such lexemes appear in texts and collocate with one another. He further adds that the potentiality of such lexemes to collocate with one another can rationally be analysed as part of the meaning of such lexemes (p. 613).

Halliday (1966) does not view lexis as part of grammatical theory, rather a complementary element thereto. He introduces the concept of 'set' as an additional dimension of word collocation. He views collocation as a co-occurrence relationship of words that come in sequence. On the other hand, he considers the set a group of members with an equal degree of occurrence in a particular collocation (Halliday, 1966, p. 153; Brashi, 2009, p. 23-24). For instance, the word 'strike' and the word 'maintain' belong to the same lexical set as they both collocate with the noun 'balance'. Sinclair (1966) views lexis and grammar from two distinct perspectives (p. 411). He asserts that patterns of language are generally dealt with in grammar in such a way that they were addressed through a system of options. Nonetheless, the key point that Sinclair (1966) is concerned with is the inclinations of lexemes to come in sequence in the form of different collocations. Such inclinations ought to inform us of important facts concerning language that can never otherwise be obtained by grammatical analysis (p. 411). He goes on to demonstrate that the contrast between different lexemes is deemed more flexible than that of classes of grammar (Sinclair, 1966, p. 411; Brashi, 2009, p. 24). One pivotal aspect of Sinclair's (1966) theory lies mainly in his distinction between significant collocation and casual collocation. He explains that a significant collocation is the one that occurs more than usual based on the particular lexemes.

Crystal (1992) contends that collocation forms a real obstacle in foreign language mastery. He then points out that the more the collocation has a fixed form, the more we believe that it is an idiom, i.e. it needs to be learned as a whole, and not in part (p. 105). This is owing to the fact that the idiomatic collective meaning of idioms cannot usually be understood from the meanings of their constituent parts, as explained earlier. Halliday \& Hasan (1976) regard collocation as 'the most problematic part' of text cohesion (p. 288). Indeed, collocations are mostly viewed as language-specific, hence, they lead to language mistakes. They may cause a problem to the foreign/second language learners as well as novice translators/interpreters when the equivalent of their mother tongue construction makes use of different collocations (Brashi, 2009, p. 24). In fact, collocations do not only cause a problem to foreign/second language learners and novice translators/interpreters, but also to native speakers, as accentuated by Palmer (1979). There is ample evidence that even some native speakers of English encounter problems in collocating specific lexemes in certain written contexts. Such problems vary depending on the writer's experience in academic writing alongside his/her education (Palmer, 1979; Hussein, 1990; Baltova, 1994; Brashi, 2009). Based on the foregoing, foreign/second language learners, including translators/interpreters should not learn a word in isolation, rather they should learn word collocations, i.e. common combinations of lexical items (Khuwaileh, 2000). This notion is in line with Faerch et al (1984), who stress the importance of learning words by way of combining them with their collocates. They argue over the merit of presenting the new words with their collocates and that would unquestionably scaffold the L2 learner by large.

Commenting on the relatively little knowledge of collocation L2 learners possess, Howarth (1998) holds the view that L2 learners are generally not informed of a considerable number of collocations. He continues to argue that it is not only L2 learners who are not cognisant of this category, however, it is an area that has received little attention in 
both lexicography and language pedagogy (p. 162). Moreover, it is claimed that even best L2 learners face certain difficulties in producing particular collocations correctly (Bonk, 2000). This is lent credence by McCarthy (1990), who contends that even advanced L2 learners may commit unacceptable or inappropriate collocations (p. 13). It seems evident that the role of the mother tongue influence is clearly responsible for the errors made in the production of the foreign/second language collocations, as shown by Hussein (1990), Biskup (1992), Bahns \& Eldaw (1993). This ipso facto proves that L2 learners generally encounter real difficulties concerning collocations regardless of their level of language proficiency. The same applies to novice translators/interpreters with varying degrees of errors, particularly when these novice translators/interpreters render texts into a language which is not their own. However, producing incorrect collocations in English by foreign/second language learners or novice translators/interpreters may well lead to the formulation of a text that sounds alien, foreign, exotic, unnatural, etc.

\section{Types of Collocation}

Collocations are commonly used in languages in general, but are frequently employed in English in particular, as demonstrated by Hill (2000). They represent almost all of the English expressions (Lewis, 2000). In crude terms, collocation can be viewed as an umbrella that generally covers all fixed expressions and phrases in all types of texts (Brashi, 2009, p. 22). Benson et al (1986) classify collocations under two main parts: lexical collocations as well as grammatical collocations. Such parts are further divided into subcategories. Lexical collocations comprise nouns, verbs, adjectives and adverbs. They usually do not include clauses, prepositions and infinitives. An example of lexical collocation is 'rich imagination', which is translated into Arabic as 'khayālun wāsi 'un, literally (wide imagination)'. The second part of collocations stated by Benson et al (1986) is grammatical collocations. They form a phrase that is normally composed of a noun and an adjective or a verb and a preposition. It can also consist of a grammatical structure containing clauses or infinitives. An example of grammatical collocation is the phrase in Chomsky's (1965) terminology, which reads as 'decide on a boat', which means 'choose to buy a boat', whereas the meaning of the said phrase as a free combination is 'pass a decision while on a boat' (Brashi, 2005). It is worth noting that grammatical collocations will be beyond the scope of the present paper, which will focus chiefly on lexical collocations. Newmark (1988) argues that the major difficulties in the work of translation are deemed lexical but not grammatical. This is owing to the fact that translating deals mainly with words, phrases, collocations and idioms (p. 32).

Another classification of collocations is provided by Newmark (1988) who classifies collocations into three categories. The first is adjective followed by a noun, whilst the second is noun followed by a noun. The last category represents a verb plus object collocation (p. 212). This runs in line with Ghazala (1995), who points out that collocation in English can appear in the form of an adjective followed by a noun, such as 'blind confidence', a noun followed by a noun, such as 'job security' and a verb followed by a noun, such as 'do a job' (p. 108). These are deemed the most commonly used types of collocations in the English language (Newmark, 1988; Ghazala, 1995; Brashi, 2005). It is worth pointing out that the present paper will deal only with the first and the third categories as the second does not usually pose problems when rendered from English into Arabic. Noun plus noun collocation is rendered into Arabic with the use of either one of the following grammatical constructions. The first is noun followed by a noun (genitive construction(, such as 'research proposal' is rendered into Arabic as 'muqtarahu bahthin'. The second is noun followed by an adjective, such as 'state university' is translated into Arabic as ‘jāmi 'atun ḥukūmiyyatun'.

\section{Issues and Problems in the Translation of Collocations}

A number of linguists, translators and interpreters have realised the concept of collocation as an obstacle or a problem; amongst those are Palmer (1979), Hussein (1990), Bahns \& Eldaw (1993), Baltova (1994), Brashi (2009), and so on. Collocational competence, which refers to the acquaintance and knowledge of collocation is unequivocally deemed a pivotal requirement for the purpose of foreign/second language mastery and therefore, for translation/interpreting. Speaking and writing a foreign/second language in the same way as that of its native speakers require observing collocations and applying them in the language production. Hence, collocational competence may well stand as a high linguistic level of language proficiency that translators/interpreters as well as foreign/second language learners should achieve (Brashi, 2009, p. 22).

The translation of collocations has long been a constant problem in the field of translation theory and practice. Translators encounter a real challenge in matching the appropriate nouns with the appropriate nouns, the appropriate adjectives with the appropriate nouns, the appropriate verbs with the appropriate nouns, etc. Such problem emanates from the fact that different languages realise and configure collocations in different ways. Furthermore, the equivalents of words that may collocate in a particular language may not necessarily collocate in another (Brashi, 
2005; Zughoul, 1991). A number of translation scholars have addressed the concept of collocation as a problematic area in translation, amongst them are Beekman \& Callow (1974), Emery (1988a; 1988b), Newmark (1988), Hatim \& Mason (1990), Baker (1992), Smadja (1993) and others. Newmark (1988) claims that realising and recognising a collocation are considered amongst the most pivotal problems in translating. He goes on to argue that translation is at times an ongoing struggle until the translator finds the appropriate collocations in the receptor language (p. 213).

Brashi (2009) claims that collocation can be viewed as a concept falling between syntax and lexis. Such notion supports the view that language competence is best described as a process of interaction between syntax and lexis (p. 22). Beekman \& Callow (1974) view the translation of collocations as an appealing feature in the translators' work and a criterion against which the competence of the translators is assessed. The translation of collocations usually demands deep knowledge as there is often no equivalence between collocational structures within different languages (p. 163). Hatim \& Mason (1990) assert that one crucial problem that often confronts the translators resides chiefly in the production of the appropriate collocations in the receptor language. They further add that the effect of the source language will always be there on the target text, even if produced by expert translators, a matter which would ultimately result in making unnatural collocations (p. 204). Baker (1992) claims that collocations across languages are generally arbitrary. Heliel (1990) believes that collocations cause real problems in translating. He goes on to explain that while free combinations are flexibly constructed, collocations pose a real challenge for translators when rendering texts from English into Arabic and vice versa. Lexical items that collocate with many other words create obstacles for translators. Translators encounter major problems in finding the appropriate equivalent in the receptor language, which may not exist in ordinary bilingual dictionaries (Brashi, 2005).

As indicated above, the present paper will discuss two types of English collocations and how they can appropriately be rendered into Arabic. This would show also the type of problems associated with the translation of collocations. The two types of collocations discussed in the current study are: verb plus object and adjective plus noun.

\subsection{Verb Plus Object}

This is a commonly employed collocation in English. Generally, English verb plus object collocations are translated into Arabic with the use of the same grammatical structure if Arabic possesses the same equivalent collocations. For instance, 'to perform a task' is translated into Arabic as 'yu' addī mahammatan, literally (perform a task)'. Evidently, the English collocation consists of the verb 'perform' which has the Arabic equivalent verb 'yu' addī' and the object 'task' which has also the Arabic equivalent noun 'mahammatan'. Hence, such English collocation is easily rendered into Arabic as it possesses an equivalent Arabic collocation which keeps the same grammatical structure intact.

At times English verb plus object collocation may be rendered into Arabic with the use of a collocation employing the same grammatical structure, but using a verb which is not the literal rendition of the English verb (Brashi, 2005). This requires full understanding of the intended collective meaning of the collocation in question, so that the translator can arrive at a TT collocation which conveys the same intended collective meaning as that of the ST collocation. This confirms the fact that translating English verb plus object collocation into Arabic is not always an easy task (Brashi, 2005). An example of this situation can be found in the English collocation 'to run an engine' which is rendered into Arabic as 'yushaghghilu muharrikan, literally (operate an engine)'. Having examined the previous example, it is obvious that the verb in the English collocation 'run' has not been translated literally into Arabic. This is due to the fact that the literal rendition of the verb 'run' into Arabic, which reads as 'yajrî', does not collocate with the Arabic noun 'muharrikan', nor does it convey the same intended meaning as that relayed by the verb 'run'. Consequently, the English verb 'run' has been rendered into Arabic with the use of the verb 'yushaghghilu' to mean the same and to collocate well with the noun 'muharrikan' which literally means 'engine'.

In certain instances, English verb plus object collocation may be rendered into Arabic with the use of a different grammatical structure. In other words, English verb plus object collocation can sometimes be translated into Arabic using verb plus preposition plus noun (Ghazala, 1995). This is a clear example of domestication, albeit at a structural level. It is claimed that any translation task involves domesticating exercise (Venuti, 2007). Such notion clearly presents the significance of adaptation in the process of establishing multilingual communication (Vandal-Sirois \& Bastin, 2012, p. 21). An example of this case can be shown in the collocation 'to pay a visit' which can be translated into Arabic as 'yaqūmu biziyāratin, literally 'pay a visit)'. It seems obvious that the foregoing example involves two essential points that merit discussion. The first lies chiefly in the fact that the verb 'pay' in the English collocation has not been translated verbatim into Arabic as 'yadfa ' $u$ '. This springs from the fact that the verb 'yadfa ' $u$ ' does not collocate with the Arabic prepositional phrase 'biziyāratin'. Moreover, The intended meaning of the English verb 'pay' in the collocation concerned is not the literal meaning. The second point associated with the example above resides mainly in the grammatical transposition that has occurred as a result of translating the noun 'visit' into a 
prepositional phrase 'biziyāratin'. Such grammatical transformation has existed as a result of the difference in type and function between the English verb and its Arabic equivalent verb. The former is transitive, i.e. it requires an object, while the latter is intransitive, i.e. it does not require an object. Hence, the exercise of the grammatical transposition on the previous example has been obligatory to arrive at the appropriate Arabic collocation. Dickins $e t$ al (2002) point out that literal translation often demands the exercise of grammatical transposition.

English verb plus object collocation may also be rendered into Arabic by way of omission. Ghazala (1995) asserts that English verb plus object collocation can exceptionally be translated into Arabic with the use of a verb. This is known as translation by omission (Dickins, et al, 2002). An example of this situation can read as 'shake hand' which is rendered into Arabic as 'yușāfị̣u, literally (shake hand)'. This example presents the difference between languages in terms of expressing different propositions. While English has required two lexical items, i.e. verb plus object to convey that a particular person makes use of his/her hand to salute another, Arabic has only needed one word, i.e. a verb to express the same proposition. The example also shows that the verb in the English collocation 'shake' has not been translated verbatim into Arabic as 'yahuzzu'. This is owing to the fact that the literal meaning of the English verb has not been intended in this very situation, however, the collective meaning of the English collocation is what has been meant.

Having examined the above, it seems evident that the translation of English verb plus object collocation into Arabic is not always a simple practice, rather it requires full awareness and deep knowledge of the meaning and structure of the collocations in both languages. English verb plus object can be flexibly rendered into Arabic with the use of the same grammatical structure if Arabic possesses the same equivalent collocation. In this very instance, the English verb and object are rendered verbatim into Arabic as the literal meaning of the English collocation is what is intended. However, in some other instances, the literal meaning of the verb in the English collocation is not intended, while the English object may correctly be translated literally into Arabic. In this case, the translator needs to find a verb in Arabic that conveys the intended collective meaning of the English collocation as well as collocates well with the Arabic object. Doing so, the English verb plus object collocation shall be translated into Arabic with the use of the same grammatical structure though the English verb has not been translated literally.

At times The grammatical structure of the English verb plus object may be sacrificed on the grounds that the translator needs to exercise grammatical transposition on the Arabic collocation and/or he/she adopts the strategy of translation by omission. These two cases may emerge if the literal meaning of the English verb is not intended, if the verbs in the English and Arabic collocations differ in terms of type and function and/or if the Arabic verb on its own conveys the intended collective meaning of the whole English verb plus object collocation. If the first two conditions are met, English verb plus object are often translated into Arabic with the use of verb plus prepositional phrase. However, if the last condition is met, English verb plus object collocation is acceptably rendered into Arabic using a verb.

\subsection{Adjective Plus Noun}

English adjective plus noun collocations are often rendered into Arabic with the use of noun pus adjective collocations (Ghazala, 1993; Brashi, 2005). This is due mainly to the fact that English and Arabic differ in terms of their word order and how different parts of speech are syntactically distributed and organized in both languages. Hence, English adjective plus noun collocations are translated into Arabic with the use of noun plus adjective collocation if Arabic possesses the same equivalent collocation. An example of this case can be illustrated by the phrase 'hard labour' which can be rendered into Arabic as 'amalun shāqun, literally (hard labour)'. Needless to say, the English adjective 'hard' has been rendered verbatim as 'shāqun' and the same applies to the English noun 'labour' which has been rendered literally as "amalun' though the word order of the Arabic collocation is reversed as a result of the difference in syntax between the two languages.

English adjective plus noun collocations can still be rendered into Arabic while keeping the same Arabic grammatical structure as the one shown above, even if the intended meaning of the English adjective is not the literal meaning. For instance, 'great pleasure' is translated into Arabic as 'sa'ādatun ghāmiratun, literally (covering pleasure)'. Having examined the example concerned, it is obvious that the English adjective 'great' has not been verbatim rendered into Arabic as "azịmatun'. One reason for this is that the literal meaning of the term is not the intended meaning in this very situation. What is more, if the literal meaning has been supposedly employed, it won't collocate with the Arabic noun 'sa'ādatun', nor will it produce an idiomatic natural target text. Conversely, the English noun 'pleasure' has been literally translated into Arabic as 'sa 'àdatun' as this is the intended meaning in this very situation. As indicated earlier, the word order of the Arabic collocation is reversed due to syntactic reasons. 
At times English adjective plus noun collocations may be rendered into Arabic with the use of the same grammatical structure though Arabic usually places the adjective after the noun. This is known as 'causative adjective' (Brashi, 2005). In such grammatical structure, the adjective is added to the noun in a genitive addition. It is noteworthy that the typical Arabic noun plus adjective collocation can still be utilised. An example of this case is the English adjective plus noun collocation 'nice weather' which can typically be rendered into Arabic with the use of the typical noun plus adjective collocation 'țaqsun 'alīlun, literally (nice weather)'. Likewise, the previous English collocation can be translated into Arabic using the same grammatical structure through genitive addition, such as "alīlu alțaqsi, literally (nice weather)'. Clearly, the English adjective 'nice' has been rendered into Arabic with the use of the Arabic adjective 'alīlu'. Similarly the English noun 'weather' has been translated into Arabic using the noun 'alțaqsi'. It is worth pointing out that such Arabic adjective plus noun collocation is not as commonly used as the Arabic noun plus adjective collocation. What is more, Arab linguists resort to the use of Arabic adjective plus noun collocations when special emphasis on the adjective is required.

English adjective plus noun collocations can sometimes have no equivalent collocations in Arabic. In This case, the translator has no choice but to exercise descriptive paraphrases to convey the intended meaning of the English collocation in question. In certain instances, even if Arabic does not possess equivalent collocation to the English collocation concerned, the translator can employ literal translation of the lexical elements that constitute the English collocation if the literal meaning of such elements is the intended meaning. Doing so, the translator may create a construction which is not deemed a collocation, however, it relays the intended meaning of the English collocation concerned. An example of this case can be shown in the English collocation 'bad news' which can be literally rendered into Arabic as 'akhbārun sayyi' atun, literally (bad news)'. Having considered the previous example, it seems evident that the English adjective 'bad' has been verbatim translated as 'sayyi' atun'. Similarly, the English noun 'news' has been literally rendered as 'akhbārun' though the word order in Arabic is reversed to fit the Arabic language norms. Nonetheless, although the Arabic phrase is a precise translation of the English collocation in question, it can never be deemed an Arabic collocation.

Having meticulously studied the present section, evidence suggests that the translation of English adjective plus noun collocations into Arabic is not always an easy task, but requires some restructuring. It at the outset requires word order reversal as Arabic usually places the adjective after the modified noun. This is a clearly significant syntactic difference between English and Arabic of which translators should take account. In crude terms, if Arabic possesses an equivalent collocation to the English adjective plus noun collocation where the literal meaning of the English collocation is the intended meaning, the translator can easily provide the Equivalent Arabic collocation as a rendition of the English collocation, with the Arabic word order reversed. Even if the literal meaning of the English adjective plus noun collocations is not intended, the translator can still find an Arabic collocation which is composed of noun plus adjective and which wholly conveys the intended collective meaning of the English collocation concerned.

English adjective plus noun collocations can at certain instances be translated into Arabic with the use of the same grammatical structure if the Arabic context demands placing special emphasis on the adjective by foregrounding it in the collocation. In this case, Arabic makes use of the genitive construction to structure such collocation. Nevertheless, the translator can still reverse the Arabic collocation to be the typical noun plus adjective collocation while receiving the same intended meaning. However, the special emphasis that has been given to the adjective will then be lost. In certain linguistic situations, the English adjective plus noun collocation has no equivalent collocation in Arabic, a situation that requires the translator to exercise descriptive paraphrases of the intended collective meaning of the English collocation concerned. However, the translator may adopt literal translation of the lexical items that form the English collocation if the literal meaning is what is intended. Doing so, the translator is viewed to have managed to translate the English collocation in question with an Arabic construction that is not considered an Arabic collocation, but a free construction.

\section{Concluding Remarks}

Evidence suggests that the concept of collocation forms a major part in any specific language. It generally points to the lexical elements that coexist in a particular discourse on condition that the meaning of the whole collocation can be deduced from at least one of its lexical elements. The mastery of foreign/second language collocations by foreign/second language learners in general, and by translators/interpreters in particular, is of paramount importance as L1 clearly affects the production of L2. Furthermore, the combination of lexical elements that do not collocate in a particular language results in producing a target text that looks exotic to the target reader and may ipso facto be incomprehensible. 
Collocation is deemed a subarea of the fixed expressions that each language enjoys, and is also considered a link between lexical items. It was first introduced by Palmer (1938) and was then developed as a technical term by Firth (1957) in his proposed theory 'meaning by collocation'. Different linguists have next propounded distinct theories to deal with collocation. Likewise, different classifications of collocations have been made by different linguists, such as Benson et al (1986) who categorise collocations under two categories: lexical and grammatical collocations. On the other hand, Newmark (1988) divides collocations into three divisions: verb plus object collocation, adjective plus noun collocation and noun plus noun collocation.

The translation of collocation has long been a real challenge for translators, particularly in finding the equivalent collocation in the receptor language that best conveys the intended meaning of that of the source language. The process of matching the appropriate nouns with the appropriate nouns, the appropriate verbs with the appropriate nouns, and so on is a formidable and arduous task, and some time poses major problems for the translator. This, of course, is due chiefly to the different and diverse ways in which languages configure collocations. Also, the equivalents of the words that do collocate in a specific language, may not necessarily collocate in another.

English verb plus object collocation is rendered into Arabic following the same grammatical structure if Arabic possesses the equivalent collocation while the literal meaning of the English collocation is the intended meaning. Even if the literal meaning of the English verb is not intended, the same grammatical structure is kept intact in Arabic, however, the difficulty that emerges here is to find the appropriate Arabic verb that can relay the intended meaning of the English verb and collocate with the Arabic object concurrently. English verb plus object collocation can at times be translated into Arabic with the use of verb plus prepositional phrase if the literal meaning of the English verb is not intended and/or the English and Arabic verbs differ in terms of type and function. Also, English verb plus object can be rendered into Arabic using a verb if the literal meaning of the English verb is not intended and the Arabic verb can relay the whole intended collective meaning of the whole English collocation. In the previous two cases, the translator has no choice but to adopt an Arabic free construction to stand for the English verb plus object collocation.

On the other hand, English adjective plus noun collocation is translated verbatim into Arabic with reversing the Arabic word order if Arabic possesses an equivalent collocation. Even if the literal meaning of the English adjective is not the intended meaning, the same Arabic grammatical structure is used. Again, the difficulty that arises here resides primarily in the collocational competence of the translator to find an Arabic adjective that does not only convey the intended meaning of the English adjective, but it also collocates with the Arabic noun properly. English adjective plus noun collocation can at times be rendered into Arabic with the use of the same grammatical structure if the Arabic context places special emphasis on the adjective by foregrounding it in the sentence concerned through the use of genitive construction. Nevertheless, the typical Arabic noun plus adjective collocation can still be used in this very situation, though the emphasis given to the adjective will unquestionably be lost if backgrounded in the sentence concerned. There are also other situations in which English adjective plus noun collocation has no equivalent collocation in Arabic, though adopting literal translation in this situation is acceptable as the intended meaning of the whole collocation is the literal meaning. Although the translator through literal translation may arrive at an appropriate and acceptable translation, his/her end result, i.e. the target text will never be considered a collocation, rather it will be deemed a free construction.

Finally, the present paper argues that the translation of English collocations into Arabic can be a flexible practice if Arabic possesses the equivalent collocation while the literal meaning of the whole English collocation is intended. The translator can still find an appropriate equivalent collocation in Arabic, even if the literal meaning of the first word in the English collocation is not intended. This, however, requires the translator to find a word in Arabic that conveys the intended meaning of the word in English and collocates with the other Arabic word simultaneously. The paper also claims that the translator may resort to make use of a free construction in Arabic to stand for the English collocation concerned. This often takes place if Arabic does not possess an equivalent collocation to the English collocation as the literal meaning of the latter is not the intended meaning, the verbs in the former and the latter differ in terms of type and function and/or the verb in the former can convey the intended meaning of the whole English collocation. This research paper has particularly addressed the translation of English verb plus object collocation and English adjective plus noun collocation into Arabic. It has been restricted to deal with specific issues pertaining to the translation of these two types of English collocation into Arabic. Further research is needed to examine the reversed process and whether or not the results will be similar to those of the present research. Important research is also required to investigate the translation of English collocations into other languages and vice versa. 


\section{References}

Bahns, J. \& Eldaw, M. (1993). Should we teach EFL students collocations? System, 21(1), 101-114. https://doi.org/10.1016/0346-251X(93)90010-E

Baker, M. (1992). In other words. $1^{\text {st }}$ ed. London/New York: Routledge.

Baltova, I. (1994). A word on collocation in English and Bulgarian. Contrastive Linguistics, 19(5), 71-75.

Beekman, J. \& Callow, J. (1974). Translating the word of God. Grand Rapids: Zondervan Publication House.

Brashi, A. (2005). Arabic collocations: Implications for translation. Unpublished PhD thesis, University of Western Sydney, Sydney.

Brashi, A. (2009). Collocability as a problem in L2 production. Reflections on English Language Teaching, 8(1), 21-34.

Benson, M., Benson, E. \& Ilson, R. (1986). The BBI combinatory dictionary of English. Amsterdam/Philadelphia: John Benjamins. https://doi.org/10.1075/z.bbi1(1st)

Biskup, D. (1992). L1 influence on learners' renderings of English collocations: A Polish/German empirical study. In P. Arnaud \& H. Bejoint (eds.), Vocabulary and applied linguistics (pp. 85-93). London: Macmillan. https://doi.org/10.1007/978-1-349-12396-4_8

Bonk, W. (2000). Testing ESL learners' knowledge of collocations. Illinois: Clearinghouse.

Bowker, L. (2002). Computer-aided translation technology: A practical introduction. Canada: University of Ottawa Press.

Chomsky, N. (1965). Aspects of the theory of syntax. Cambridge/Mass.: MIT Press.

Cruse, D. (1986). Lexical semantics. Cambridge: Cambridge University Press.

Crystal, D. (1992). The Cambridge encyclopedia of language. Cambridge: Cambridge University Press.

Dickins, J., Hervey, S. \& Higgins, I. (2002). Thinking Arabic translation: A course in translation method: Arabic to English. Oxon: Routledge.

Emery, P. (1988a). Body-part collocations and idioms in Arabic and English: A contrastive study. Unpublished PhD, University of Manchester, Manchester.

Emery, P. (1988b). Collocation: A problem in Arabic/English translation? Quinquereme, 11(1), 178-184.

Faerch, C., Haastup, K. \& Philipson, r. (1984). Learner language and language learning. Clevedon: Multilingual Matters.

Firth, J. (1957). Modes of meaning. In F. Palmer (ed.), Papers in linguistics (pp. 190-215). London: Oxford University Press.

Firth, J. (1968). A synopsis of linguistic theory. In F. Palmer (ed.), Selected papers of J.R. Firth 1952-1959 (pp. 168-205). London: Longman.

Ghazala, H. (1993). Translating collocations: English-Arabic (in Arabic). Turjuman, 2(2), 7-33.

Ghazala, H. (1995). Translation as problems and solutions. Valetta: Elga.

Halliday, M. (1966). Lexis as a linguistic level. In C. Bazell, J. Catford, M. Halliday \& R. Robins (eds.), In memory of J.R. Firth (pp. 148-162). London: Longman.

Halliday, M. \& Hasan, R. (1976). Cohesion in English. London: Longman.

Hatim, B. \& Mason, I. (1990). Discourse and the translator. London: Longman.

Hatim, B. \& Mason, I. (1997). Translator as Communicator. London: Routledge.

Heliel, M. (1990). Collocations and translation (in Arabic). Nouvelles de la Federation Internationale des Traducteurs- FIT Newsletter, 9(3), 31-50.

Hill, J. (2000). Revising Priorities: From grammatical failure to collocational success. In M. Lewis (ed.), Teaching collocation: Further developments in the lexical approach (pp. 47-69). Hove: Language Teaching Publications.

Hoogland, J. (1993). Collocations in Arabic (MSA) and the treatment of collocations in Arabic dictionaries. The Arabist: Budapest Studies in Arabic, 6-7(1), 75-93. 
Howarth, P. (1998). Phraseology and second language proficiency. Applied Linguistics, 19(1), 24-44. https://doi.org/10.1093/applin/19.1.24

Hussein, R. (1990). Collocations: The missing link in vocabulary acquisition amongst English foreign learners. In J. Fisiak (ed.), Papers and studies in contrastive linguistics. The Polish/English contrastive project (vol. 26, pp. 123-136). Pozan: Adam Mickiewicz University.

Khuwaileh, A. (2000). Vocabulary in LSP: A case study of phrases and collocations. Babel, 46(1), 97-111. https://doi.org/10.1075/babel.46.2.02khu

Lewis, M. (ed.), (2000). Teaching collocation: Further developments in the lexical approach. Hove: Language Teaching Publications.

Lyons, J. (1966). Firth's theory of meaning. In C. Bazell, J. Catford, M. Halliday \& R. Robins (eds.), In memory of J.R. Firth (pp. 288-302). London: Longman.

Lyons, J. (1977). Semantics. London: Cambridge University Press. https://doi.org/10.1017/CBO9781139165693

Mahadi, T. S. T., Vaezian, H. \& Akbari, M. (2010). Corpora in translation: A practical guide. Bern: Peter Lang.

McCarthy, M. (1990). Vocabulary. Oxford: Oxford University Press.

Newmark, P. (1988). A textbook of translation. New York: Prentice Hall.

Palmer, F. (1979). Semantics. Cambridge: Cambridge University Press.

Palmer, H. (1938). A grammar of English words. London: Longman.

Robins, R. (1967). A short history of linguistics. London: Longman.

Sinclair, J. (1966). Beginning the study of lexis. In C. Bazell, J. Catford, M. Halliday \& R. Robins (eds.), In memory of J.R. Firth (pp. 410-430). London: Longman.

Smadja, F. (1993). Retrieving collocations from text: Xtract. Computational Linguistics, 19(1), 143-177.

Vandal-Sirois, H. \& Bastin, G. L. (2012). Adaptation and appropriation: Is there a limit? In L. Raw (ed.), Translation, adaptation and transformation (pp. 21-41). London: Continuum International Publishing Group.

Venuti, L. (2007). Adaptation, translation, critique. Journal of Visual Culture, 6(1), 25-43. https://doi.org/10.1177/1470412907075066

Zughoul, M. (1991). Lexical choice: Towards writing problematic word Lists. IRAL, 19(1), 45-60. https://doi.org/10.1515/iral.1991.29.1.45 